\title{
In vitro Antioxidant Activity of Methanolic and Ethanolic Extracts of seeds of Macrotyloma uniflorum
}

\author{
Subramani Parasuraman*, Vanishya A/P Raipan
}

Subramani Parasuraman*, Vanishya A/P Raipan

Faculty of Pharmacy, AIMST University, MALAYSIA.

\section{Correspondence}

S. Parasuraman, M.Pharm., Ph.D.,

Department of Pharmacology, Faculty of Pharmacy, AIMST University, 08100 Bedong, Kedah, MALAYSIA.

E-mail: parasuraman@aimst.edu.my

History

- Submission Date: 06-04-2021;

- Review completed: 07-05-2021.

- Accepted Date: 18-06-2021.

DOI : 10.5530/fra.2021.1.5

Article Available online

http://www.antiox.org

Copyright

(C) 2021 Phcog.Net. This is an openaccess article distributed under the terms of the Creative Commons Attribution 4.0 International license.

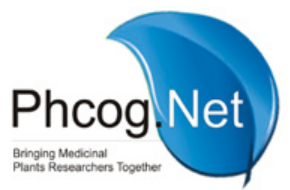

\begin{abstract}
Objectives: To study the antioxidant activity of methanolic and ethanolic extracts of seeds of Macrotyloma uniflorum. Methods: The seeds of $M$. uniflorum were extracted with methanol and ethanol and used for the phytochemical analysis and determination of antioxidant activity. The in vitro antioxidant activity was studied using 2,2-diphenyl-1-picrylhydrazyl (DPPH) and hydroxyl radical scavenging methods. Result: Ethanolic extracts of $M$. uniflorum showed more phenolic content (63.48 mg GAE/g) than methanolic extract of $M$. uniflorum (45.84 mg GAE/g). In total flavonoid content analysis, methanolic and ethanolic extracts of $M$. uniflorum showed the presence of flavonoid content of $15.31 \mathrm{mg}$ Rutin/g and $15.44 \mathrm{mg}$ Rutin/g, respectively. In DPPH assay, methanolic and ethanolic extracts of $M$. uniflorum exhibited $50 \%$ free radical scavenging activity at $797.71 \pm 34.38 \mu \mathrm{g} / \mathrm{mL}$ and $938.80 \pm 66.05 \mu \mathrm{g} / \mathrm{mL}$ (mean \pm standard deviation; $n=3$ ), respectively. In hydroxyl radical scavenging assay, methanolic and ethanolic extracts of $M$. uniflorum exhibited $50 \%$ fee radical scavenging activity at $770.27 \pm 11.64 \mu \mathrm{g} /$ $\mathrm{mL}$ and $844.94 \pm 35.12 \mu \mathrm{g} / \mathrm{mL}$ (mean \pm standard deviation; $n=3$ ), respectively. Ascorbic acid exhibited potent free radical scavenging with $\mathrm{IC}_{50}$ value of $60.54 \pm 5.23 \mu \mathrm{g} / \mathrm{mL}$ in DPPH method and $207.98 \pm 14.26 \mu \mathrm{g} / \mathrm{mL}$ (mean \pm standard deviation; $n=3$ ) in hydroxyl radical scavenging method. Conclusion: Ethanolic extracts of $M$. uniflorum showed more phenolic content than methanolic extract of $M$. uniflorum. In both, DPPH and hydroxyl radical scavenging assay, methanolic and ethanolic extracts of $M$. uniflorum exhibited antioxidant activity at higher concentration.
\end{abstract}

Key words: 2,2-diphenyl-1-picrylhydrazyl (DPPH), Free radical, Hydrogen peroxide $\left(\mathrm{H}_{2} \mathrm{O}_{2}\right)$.

\section{INTRODUCTION}

The plants are mankind and many drugs are isolated from the plant which includes atropine, digoxin, etc. In $19^{\text {th }}$ century many of the drugs are isolated from the plant which is now used for therapeutic purposes. In Ayurveda, Siddha and Traditional Chinese Medicine (TCM) herbs are the main ingredients for the formulation.

Macrotyloma uniflorum (horse gram) belongs to the family Fabaceae and widely distributed throughout Asia, Africa and Australia. ${ }^{2}$ M. uniflorum is the one of the important herbs which is used as food grain and rich in protein. It is lesser-known beans and is normally used to feed horses. In Ayurveda, the seeds of $M$. uniflorum are used to treat jaundice or water retention and as part of a weight-loss diet. ${ }^{3}$ Different parts of this plant are used for the treatment of asthma, bronchitis, leukoderma, urinary discharges and for the treatment of kidney stones. ${ }^{4}$ It is considered an excellent source of dietary fibre, molybdenum, iron, calcium and other micronutrients. In the classical Indian texts like Charak Samhita and Sushruta Samhita about traditional Indian medicinal system, the seeds of $M$. uniflorum are known to cure abdominal lump, bronchial asthma, hiccup, piles and also in regulating or stopping excessive perspiration. ${ }^{5}$ The antioxidant properties of extracts of seeds of $M$. uniflorum are not well studied. Hence the present study is to plan to study the antioxidant properties of methanolic and ethanolic extracts of seeds of $M$. uniflorum.

\section{MATERIALS AND METHODS}

\section{Collection of seeds of M. uniflorum}

The seeds of M. uniflorum were purchased in the local market in Sungai Petani, Malaysia.

\section{Extraction}

The dried seeds of $M$. uniflorum were powdered and was packed in a Soxhlet extractor and extracted with methanol $65 \pm 5^{\circ} \mathrm{C}$ and $95 \%$ ethanol at $75 \pm 5^{\circ} \mathrm{C}$. The extraction was carried out for $72 \mathrm{hr}$ or for $3-4$ cycles. The methanolic extract of seeds of $M$. uniflorum (MEMU) and ethanolic extract of seeds of M. uniflorum (EEMU) was filtered was concentrated to a dry mass by evaporation under reduced pressure 
using a rotary evaporator (Rotavapor ${ }^{\circledast}$ R-210, BUCHI Corporation). The MEMU and EEMU were stored at room temperature until use.

\section{Phytochemical analysis}

One gram of MEMU and EEMU was dissolved in $100 \mathrm{ml}$ of its own mother solvent and a stock of concentration $1 \% \mathrm{w} / \mathrm{v}$ was obtained and tested for the presence of carbohydrates, proteins, sterols, alkaloids, tannins, glycosides, flavonoids, phenolic compounds, and saponins. ${ }^{6}$

\section{Determination of total phenolic content}

The total phenolic content in MEMU and EEMU was determined by the Folin-Ciocalteu method and gallic acid was used as a standard equivalent (in $\mathrm{mg}$ GAE/g). Approximately, $500 \mu \mathrm{l}$ of Folin-Ciocalteu reagent were mixed to $100 \mu \mathrm{l}$ diluted M. uniflorum extracts. After $5 \mathrm{~min}, 400 \mu \mathrm{l} 7.5 \%$ sodium carbonate was added to the mixture and stand for $30 \mathrm{~min}$ at room temperature. The absorbance was measured spectrophotometrically at $765 \mathrm{~nm}$ (Model UV 1800, Shimadzu, Japan). ${ }^{7}$

\section{Determination of total flavonoid content}

The total flavonoid content of the crude extract was determined by the aluminum chloride colourimetric method. $0.5 \mathrm{ml}$ of each extract was mixed with $0.5 \mathrm{ml}$ aluminum chloride (2\%), and then $3 \mathrm{ml}$ potassium acetate $(5 \%)$ was added. The solution was left for $40 \mathrm{~min}$ at room temperature and the absorbance of the reaction mixture was measured at $415 \mathrm{~nm}$. The calibration curve was plotted by different concentration of rutin equivalents (in mg Rutin/g). ${ }^{8,9}$

\section{Determination of antioxidant activity}

2,2-diphenyl-1-picrylhydrazyl (DPPH) radicals scavenging activity: Extracts $(0.2 \mathrm{ml})$ at different concentrations $(400-1000 \mu \mathrm{g} / \mathrm{ml})$ was mixed with $0.8 \mathrm{ml}$ of tris hydrochloric acid $(\mathrm{HCl})$ buffer $(100 \mathrm{mM}$; $\mathrm{pH} 7.4)$. One millilitre DPPH (500 mM in $1.0 \mathrm{ml}$ ethanol or methanol) solution was added to the mixture. The mixture was shaken vigorously and incubated for $30 \mathrm{~min}$ at room temperature. The absorbance of the resulting solution was measured spectrophotometrically at $517 \mathrm{~nm}$. Vitamin C was used as a standard antioxidant in this method. Percentage (\%) of DPPH scavenging activity was determined using [(Absorbance of control - Absorbance of test sample)/ Absorbance of control) $\times 100]) \cdot{ }^{10,11}$ All the determinations were carried out in triplicate.

Hydroxyl radical scavenging assay: A solution of hydrogen peroxide $\left(\mathrm{H}_{2} \mathrm{O}_{2}\right)(40 \mathrm{mM})$ was prepared in phosphate buffer, $\mathrm{pH}$ 7.4. The extracts $(400-1000 \mu \mathrm{g} / \mathrm{ml})$ in Dimethyl sulfoxide (DMSO) was added to a hydrogen peroxide solution and at $230 \mathrm{~nm}$, the absorbance was determined after 10 min against the blank solution containing phosphate buffer without hydrogen peroxide. Ascorbic acid was used as a standard. ${ }^{12}$ Percentage inhibition was determined using [(Absorbance of control - Absorbance of test sample)/ Absorbance of control) $\times 100$ ]. All the determinations were carried out in triplicate.

\section{RESULTS}

\section{Phytochemical screening}

MEMU showed the presence of alkaloid, amino acids, flavonoid, glycoside, mucilage, saponin, steroid, tannins and phenolic compounds, and EEMU showed the presence of alkaloid, amino acids, flavonoid, saponin, steroid, tannins and phenolic compounds.

\section{Total phenolic content}

Gallic acid is used as the standard for total phenolic content analysis. The standard concentration course was constructed using 100, 200, 400, 600, 800 and $1000 \mu \mathrm{g} / \mathrm{mL}$ concentrations. Ethanolic extracts of M. uniflorum
Table 1: Total phenolic and flavonoid content.

$\begin{array}{ccc}\text { Analysis } & \text { Extract } & \text { Content of phytoconstituents } \\ \text { Total phenolic } & \text { Methanolic extract } & 45.84 \mathrm{mg} \mathrm{GAE} / \mathrm{g} \\ \text { content } & \text { Ethanolic extract } & 63.48 \mathrm{mg} \mathrm{GAE} / \mathrm{g} \\ \text { Total flavonoid } & \text { Methanolic extract } & 15.31 \mathrm{mg} \mathrm{Rutin} / \mathrm{g} \\ \text { content } & \text { Ethanolic extract } & 15.44 \mathrm{mg} \text { Rutin/g }\end{array}$

showed more phenolic content than methanolic extract of M. uniflorum (Table 1).

\section{Total flavonoid content}

Rutin is used as the standard for total flavonoid content analysis. The standard concentration course was constructed using 100, 200, 400, 600, 800 and $1000 \mu \mathrm{g} / \mathrm{mL}$ concentrations. Methanolic and ethanolic extracts of M. uniflorum showed the presence of flavonoid content of $15.31 \mathrm{mg}$ Rutin/g and $15.44 \mathrm{mg}$ Rutin/g, respectively (Table 1).

\section{Antioxidant Activity}

In the DPPH method, ascorbic acid exhibited potent free radical scavenging property than methanolic and ethanolic extracts of $M$. uniflorum with $\mathrm{IC}_{50}$ value of $60.54 \pm 5.23 \mu \mathrm{g} / \mathrm{mL}$ (mean \pm standard deviation; $n=3$ ). Methanolic and ethanolic extracts of M. uniflorum exhibited $50 \%$ free radical scavenging activity at $797.71 \pm 34.38 \mu \mathrm{g} / \mathrm{mL}$ and $938.80 \pm 66.05 \mu \mathrm{g} / \mathrm{mL}$ (mean \pm standard deviation; $n=3$ ), respectively. In $\mathrm{H}_{2} \mathrm{O}_{2}$ method, ascorbic acid exhibited potent free radical scavenging property than methanolic and ethanolic extracts of $M$. uniflorum with $\mathrm{IC}_{50}$ value of $207.98 \pm 14.26$ (mean \pm standard deviation; $n=3$ ). Methanolic and ethanolic extracts of $M$. uniflorum exhibited $50 \%$ free radical scavenging activity at $770.27 \pm 11.64 \mu \mathrm{g} / \mathrm{mL}$ and $844.94 \pm 35.12$ $\mu \mathrm{g} / \mathrm{mL}$ (mean \pm standard deviation; $n=3$ ), respectively.

In both, DPPH and hydroxyl radical scavenging assay, Vitamin C showed a potent antioxidant effect whereas methanolic and ethanolic extracts of M. uniflorum exhibited antioxidant activity at higher concentration.

\section{DISCUSSION}

The methanolic and ethanolic extracts of M. uniflorum exhibited antioxidant activity in DPPH and hydroxyl radical scavenging assay at higher concentration. Thippeswamy et al. reported the antioxidant activity (studied using the DPPH method) of M. uniflorum and estimated ascorbic acid content by dinitrophenylhydrazine (DNPH) method. ${ }^{13}$ The results showed ascorbic acid content found to be $20.80 \mathrm{mg}, 20.88$ $\mathrm{mg}, 30.08 \mathrm{mg}$ and $30.27 \mathrm{mg} / 100 \mathrm{~g}$ at $6,12,18$ and $24 \mathrm{~h}$. The changes in the ascorbic acid content were further monitored calorimetrically in the extracts of germinating seeds after germination for 2 to 7 days and were found to be $45.08,46.94,52.77,38.05,34.52$ and $30.75 \mathrm{mg} / 100 \mathrm{~g}$ seeds respectively. The ascorbic acid and total antioxidant activity were estimated and the results showed a good amount of ascorbic acid and total antioxidant activity in germinating seeds. ${ }^{13}$ Ascorbic acid is a known antioxidant and this may be responsible for the antioxidant activity of the seeds of M. uniflorum. In the present study, the antioxidant properties of M. uniflorum were studied using its dry seeds. Further studies are required to compare the antioxidant properties of dry and germinated seed extracts of M. uniflorum.

Singh et al., studied the in vitro antioxidant activities of methanol extract of Dolichos biflorus (Synonym of M. uniflorum) dal commonly edible food from central Himalayans. Total phenolic and flavonoid contents of methanolic extract of Dolichos biflorus dal was $92.10 \pm 8.11 \mathrm{mg} / \mathrm{ml} \mathrm{GAE}$ per $100 \mathrm{mg}$ plant extract and $139.5 \pm 55.09 \mathrm{mg} / \mathrm{ml}$ (mean \pm standard 
deviation) quercetin equivalent per $100 \mathrm{mg}$ plant extract respectively, and it showed 4 times greater free radical scavenging activity than that of the synthetic antioxidant ascorbic acid. The study showed that Dolichos biflorus exhibited antioxidant activity against DPPH and $\mathrm{H}_{2} \mathrm{O}_{2}$ induced free radicals. ${ }^{14}$

The seeds of $M$. uniflorum have antioxidant, antihyperlipidemic, antimicrobial and diuretic activities and used for the management of coronary heart diseases. ${ }^{15,16}$ Varicola et al., studied the antioxidant and anthelmintic activities of various extract of $M$. uniflorum and reported that the methanolic extract has significant anthelmintic activities with $\mathrm{IC}_{50}$ values of $3.86 \mu \mathrm{g} / \mathrm{ml}^{3}$ Pritha et al., studied the antimicrobial and cytotoxic effects of methanol and ethanol extracts of $M$. uniflorum extract and the results showed significant antimicrobial and antioxidant activity and anticancer activity against MG-63 cell line. ${ }^{17}$ The extracts of M. uniflorum also exhibited significant analgesic, anti-inflammatory, diuretic hepatoprotective and cardioprotective activities. ${ }^{18-20}$ These activities may be mediated through the antioxidant properties of seeds of M. uniflorum.

\section{CONCLUSION}

Ethanolic extracts of $M$. uniflorum showed more phenolic content than methanolic extract of $M$. uniflorum. In total flavonoid content analysis, both methanolic and ethanolic extract exhibited an equal amount of flavonoid content. In both, DPPH and hydroxyl radical scavenging assay, vitamin $\mathrm{C}$ showed a potent antioxidant effect whereas methanolic and ethanolic extracts of $M$. uniflorum exhibited antioxidant activity at higher concentration.

\section{CONFLICT OF INTEREST}

The authors declare no conflict of interest.

\section{ABBREVIATIONS}

DNPH: Dinitrophenylhydrazine; DPPH:2,2-diphenyl-1-picrylhydrazyl; EEMU: Ethanolic extract of seeds of M. uniflorum; g: Gram; GAE: Gallic acid; $\mathrm{H}_{2} \mathrm{O}_{2}$ : Hydrogen peroxide; $\mathrm{HCl}$ : Hydrochloric acid; MEMU: Methanolic extract of seeds of M. uniflorum; mg: Milligram; TCM: Traditional Chinese Medicine.

\section{REFERENCES}

1. Parasuraman S. Herbal drug discovery: challenges and perspectives. Curr Pharmacogenomics Pers Med. 2018;16(1):63-8. doi: 10.2174/18756921166661 80419153313

2. Chavan JK, Kadam SS. Nutritional improvement of cereals by sprouting. Crit Rev Food Sci Nutr. 1989;28(5):401-37. doi: 10.1080/10408398909527508, PMID 2692609.
3. Marimuthu M, Krishnamoorthi K. Nutrients and functional properties of horse gram (Macrotyloma uniflorum), an underutilized south Indian food legume. J Chem Pharm Res. 2013;5(5):390-4.

4. Sree VK, Soundarya M, Ravikumar M, Reddy TR, Durgadevi NK. In vitro screening of Macrotyloma uniflorum extracts for antioxidant and anthelmintic activities. J Pharmacogn Phytochem. 2019;3(4):06-10.

5. Ramesh C, Ramesh A, Prabhakar B, Vijay Avin B, Aditya Rao S. Antioxidant potentials in sprouts vs. seeds of Vigna radiata and Macrotyloma uniflorum. J Appl Pharm Sci. 2019;1(7):99-103.

6. Ali S, Khan MR, Irfanullah, Sajid M, Zahra Z. Phytochemical investigation and antimicrobial appraisal of Parrotiopsis jacquemontiana (Decne) Rehder. BMC Complement Altern Med. 2018;18(1):43. doi: 10.1186/s12906-018-2114-z. PMID: 29386016.

7. Derakhshan Z, Ferrante M, Tadi M, Ansari F, Heydari A, Hosseini MS, Conti GO, Sadrabad EK. Antioxidant activity and total phenolic content of ethanolic extract of pomegranate peels, juice and seeds. Food Chem Toxicol. 2018;114:108-11. doi: 10.1016/j.fct.2018.02.023, PMID 29448088.

8. Baba SA, Malik SA. Determination of total phenolic and flavonoid content, antimicrobial and antioxidant activity of a root extract of Arisaema jacquemonti Blume. J Taibah Unv Sci. 2015;9(4):449-54. doi: 10.1016/j.jtusci.2014.11.001.

9. Derakhshan Z, Ferrante M, Tadi M, Ansari F, Heydari A, Hosseini MS, Conti GO, Sadrabad EK. Antioxidant activity and total phenolic content of ethanolic extract of pomegranate peels, juice and seeds. Food Chem Toxicol. 2018;114:108-11. doi: 10.1016/j.fct.2018.02.023, PMID 29448088.

10. Sharma US, Kumar A. In vitro antioxidant activity of Rubus ellipticus fruits. J Adv Pharm Technol Res. 2011;2(1):47-50. doi: 10.4103/2231-4040.79805, PMID 22171292.

11. Olugbami JO, Gbadegesin MA, Odunola OA. In vitro free radical scavenging and antioxidant properties of ethanol extract of Terminalia glaucescens. Pharmacogn Res. 2015;7(1):49-56. doi: 10.4103/0974-8490.147200, PMID 25598635

12. Bukhari NA, Al-Otaibi RA, Ibhrahim MM. Phytochemical and taxonomic evaluation of Rhazya stricta in Saudi Arabia. Saudi J Biol Sci. 2017;24(7):1513-21. doi: 0.1016/j.sjbs.2015.10.017, PMID: 30294220.

13. Thippeswamy TG, Sunilkumar HS. Ascorbic acid and antioxidant activity in germinating horse gram (Macrotyloma uniflorum) seeds. Int J Pharm Pharm Res. 2018;14(1):118-29.

14. Singh R, Singh MK, Chandra LR, Arora MS, Naiwal TK, Pande V. In vitro Antioxidant and free radical scavenging activity of Dolichos biflorus (Gahat dal) from Kumauni region. Int J Fundam Appl Sci. 2012;1:9-11.

15. M.A. Kawsa SM, Seraj Uddi M, Huq E, Nahar N, OzekiY. Biological investigation of Macrotyloma uniflorum Linn. extracts against some pathogens. J Biol Sci. 2008;8(6):1051-6. doi: 10.3923/jbs.2008.1051.1056.

16. Kawsar SMA, Huq E, Nahar N, Ozeki Y. Identification and quantification of phenolic acids in Macrotyloma uniflorum by reversed phase HPLC. Am J Plant Physiol. 2008;3(4):165-72. doi: 10.3923/ajpp.2008.165.172.

17. Chakraborty P, Abraham J. Antimicrobial and cytotoxic effects of Macrotyloma uniflorum extract. Int J Pharm Pharm Res. 2016;8(8):1334-40.

18. Ashraf J, Baig SG, Ahmed S, Hasan MM. Analgesic, anti-inflammatory and diuretic activities of Macrotyloma uniflorum (Lam.) Verdc. Pak J Pharm Sci. 2018;31(5):1859-63. PMID 30150181.

19. Panda V, Laddha A, Nandave M, Srinath S. Dietary phenolic Acids of Macrotyloma uniflorum (Horse Gram) protect the rat heart against isoproterenol-induced myocardial infarction. Phytother Res. 2016;30(7):1146-55. doi: 10.1002/ptr.5620, PMID 27091200.

20. Bhaargavi Y, Jyotsna GSL, Tripurana R. A review on hepatoprotective activity. Int J Pharm Sci Res. 2014;5(3):690-02.

Cite this article: Parasuraman S, Raipan VA/P. In vitro Antioxidant Activity of Methanolic and Ethanolic Extract of seeds of Macrotyloma uniflorum. Free Radicals and Antioxidants. 2021;11(1):24-6. 